\title{
General Assumption of Psychological Behavior Based on Finger Print Pattern
}

\author{
Kishore Kumar Agarwal (Corresponding Author) \\ Assistant professor (Anatomy) \\ Veer Chandra Singh Garhwali Govt. Medical Sciences and Research Institute \\ Srinagar, ( Pauri-Garhwal), Uttarakhand, India \\ E-mail: drkkanatomy@gmail.com \\ Hemant Kumar Dutt \\ Govt. Medical College, Haldwani, Uttarakhand, India

\begin{abstract}
Alok Saxena
Veer Chandra Singh Garhwali Govt. Medical Sciences and Research Institute Srinagar, Uttarakhand, India

E-mail: alok.sxna@gmail.com
\end{abstract}

Deepak Dimri, Daulat Singh \& Naveen Bhatt

Veer Chandra Singh Garhwali Govt. Medical Sciences and Research Institute Srinagar, Uttarakhand, India

Received: February 1, 2012 Accepted: February 15, 2012

doi:10.5296/jbls.v3i1.1499 URL: http://dx.doi.org/10.5296/jbls.v3i1.1499 


\section{Abstract}

The impressions from the pulp of finger are known as fingerprints. Using fingerprints to identify individuals has become an invaluable tool worldwide. A Study of finger print pattern was performed in the prisoners and normal population (non prisoners) of hilly region to compare whorls, loops, arches and composites in each hand using ink technique. The goal of the study was to identify the behavioral traits (somatic, psychological and Neurological) of these two groups on the basis of finger print pattern. Prevalence of whorls and arches were more in right hand of control group as compare to prisoners. On contrary, loops were found more in right hand of prisoners than control group. Left hand of control and prisoners showed following results: whorls and arches in control group > prisoners and loops in prisoners > control group. Aforementioned Results were found statistically significant.

Keywords: Arch, Composite, Loop, Prisoners, Whorl

\section{Introduction}

The feasibility and permanency of fingerprint (FP) is well known and already used by ancient Assyrians and Chinese for identification of a person. The scientific study of finger printing was initiated in late $16^{\text {th }}$ century but modern FP identification methods were came in to picture at the end of $19^{\text {th }}$ century. A study was performed by Galton and Henry to establish print as legal sign of identification by law enforcement agencies. Finger print recognition in the basic task of the integrated automated finger print identification service (IAFIS) was initially developed in 1950 by FBI in cooperation with national bureau of standard (Cass county).

The skin on the volar aspect of the fingers is corrugated with the ridges and configurations, known as FP. The term, dermatoglyphics, a study of finger print was coined by Cummins (Cummins HM., 1926)). The dermatoglyphics patterns are developed during $12^{\text {th }}$ to $13^{\text {th }}$ week of intrauterine life and remain unchanged throughout life (Kiran et al., 2010). Dactyloscopy, fingerprint identification or palm print identification is the process of comparing two instances of friction ridge skin impressions of fingers, palm or toes in human being to determine whether these impressions belong to the same individual (Ashbaugh DR., 1991).

Exemplar prints is the terms used for collected specimen from a subject for the enrollment in a system and in case of suspected criminal offense. During criminal arrest a set of exemplar prints normally include a print from each finger by rolling it from one edge of the nail to the other, plain impressions of the four fingers of each hand and each thumb. Exemplar prints can be collected using live scan or by using ink on paper cards (Kanhere AM., 2012).

Three basic patterns were categorized by Henry system of classification into loop, whorl and arch which constitute 60-65\%, 30-35\% and 5\% of all FP respectively (Henry ER., 1900). Whorl pattern is commonly found in certain types of criminals as described by Noel Jaquin in 1933. Aquin (1940) described the general features of each of finger impression. Gettings also recognized the three essential types of prints as described by Henry system of classification. Beryl B. Hutchinson observed that the dermatoglyphic patterning demonstrated the individual's personality tools inherited from birth. White described four patterns named whorl, 
loop, arch and composite without differentiations between ulnar and radial or tented and simple arches or other features. The Japanese palmist Asano relied on loop, arch and whorl. Katakkar described that the finger impressions show the hereditary character of a person (Campbell ED., 1998).

\section{Materials and Methods}

A comparative study involving two groups, control population and prisoners belong to the north Indian hilly population was performed to observe their FP patterns. Samples were collected from 300 hands (both right and left) belong to each group. Choice of FP impressions procedure was based on ink technique due to its feasibility. Subjects were asked to wash their hands thoroughly and dried. Thereafter, fingers and thumb of each hand were pressed against stamp pad followed by impressions on white paper. Subjects were also advised to roll their finger pads from one side of the nail to other. Finger prints were carefully observed using magnifying hand lens. The whorl, loop, arch and composite of each fingers were noticed and documented on the basis of ridges and furrows. Study was not gender and age biased. Faded, overlapped and impressions with excessive ink were excluded from the study.

\section{Statistical Analysis}

Data collected from both right and left hands belong to control and prisoner groups were compared using Chi- square test. Level of Significance was set at $\mathrm{P}<0.05$.

Table 1. Showing Right hand FP patterns in Control group and Prisoners

\begin{tabular}{|llcl|}
\hline \multicolumn{1}{|c}{$\begin{array}{c}\text { Finger print } \\
\text { pattern }\end{array}$} & \multicolumn{1}{c}{$\begin{array}{c}\text { Right Hand (Control) } \\
\text { (frequencies) }\end{array}$} & $\begin{array}{c}\text { Right Hand (Prisoner) } \\
\text { (frequencies) }\end{array}$ & $\begin{array}{c}\text { P } \\
\text {-value }\end{array}$ \\
\hline Whorl & 308 & 253 & .002 \\
\hline Loop & 345 & 431 & .002 \\
\hline Arch & 57 & 34 & .015 \\
\hline Composite & 40 & 32 & .345 \\
\hline
\end{tabular}

Table 2. Showing Left hand FP patterns in Control group and Prisoners

\begin{tabular}{|llclc|}
\hline \multicolumn{1}{|c}{$\begin{array}{c}\text { Finger print } \\
\text { pattern }\end{array}$} & \multicolumn{1}{c}{$\begin{array}{c}\text { Left Hand (Control) } \\
\text { (frequencies) }\end{array}$} & $\begin{array}{c}\text { Left Hand (Prisoner) } \\
\text { (frequencies) }\end{array}$ & $\begin{array}{c}\text { P } \\
\text {-value }\end{array}$ \\
\hline Whorl & 261 & 183 & .0002 \\
\hline Loop & 357 & 478 & .0000 \\
\hline Arch & 67 & 41 & .0124 \\
\hline Composite & 65 & 48 & .1098 \\
\hline
\end{tabular}

\section{Results}

In present study, whorl, loop and arch were found to be significant in both right and left hand. Whorls and arches were more in both hands of control population while loops were more in right and left hand of prisoners. Results of composite group were insignificant. 


\section{Discussion}

A study conducted by Noel Jaquin revealed that people with more number of whorls were independent and very individualistic. White concluded that whorl makes a person very selective and otherwise noncommittal (Campbell ED., 1998).

In current study, whorls in right hand of control and prisoners were observed with $41.06 \%$ and $33.73 \%$ respectively. Whorls in Left hand of control group were recorded as $34.8 \%$ in compare to prisoner with $24.4 \%$ (Table 1,2). We found more number of whorls in control group showing positive psychological features as defined by Jaquin and White (Figure: 1).

Individuals with more number of loops were found to be possible lack of concentration, adaptable, versatile and emotionally responsive. White indicates an active, outgoing person with a love of "progress", who may be motivated by either feelings of responsibility or desire to be prominent and involved in the limelight (Campbell ED., 1998). Present study showed $46 \%$ loops in right hand of control group and $57.47 \%$ in same hand of prisoners (Figure: 2). We also found left hand of control group and prisoners with a percentage of $47.6 \%$ and $63.73 \%$ respectively (Table 1,2). Characteristic features explained by Jaquin match with mental behavior of prisoners whereas psychological features of prisoners were not consistent with views of White.

Individuals with greater frequencies of arches were characterized as contained, repressive, secretive in self defense, naturally suspicious and resentful of others achievements. Gettings defined these people as crude, insensitive, hard heartened and defiantly stubborn. Katakkar found subjects with this print high strung, nervous and too easily responsive to emotional stimulation (Campbell ED., 1998). In present study, control group were found with greater percentage of arch in both right and left hand as compared to left hand. Percentage of arches in right hand of control group was calculated $7.6 \%$ while prisoners were with $4.53 \%$. Arches in left hand of former group were recorded as $8.93 \%$ and latter with $5.47 \%$. Our study does not support the views of abovementioned authors to describe the personality of an individual. No significant results were observed in composite pattern of both groups (Table 1,2).

\section{Conclusion}

The study points at a putative correlation between the pattern of finger prints and personalities of individuals which is in consort with previous published works. It brings in light the deviant nature of individuals and could actually be employed as a tool to tailor person specific counseling regimes towards ensuring healthier attitudes of those individuals.

\section{Acknowledgement}

We are grateful to Edward D Campbell for giving his consent to use the data for this study. We also thank Mr. TD Joshi, Mr. Mrinmoy Chakrabarty (Dept. of Pharmacology), Ayushi Agarwal and Mr. Rakesh Pal Singh Negi for their contribution to carry out this work.

\section{References}

Ashbaugh David R. (1991). Ridgeology. Journal of Forensic Identification, 41.

Campbell ED (1998). Fingerprints \& palmar dermatoglyphics. [Online] Available: http://www.edcampbell.com/PalmD-History.htm (1998). 


\section{Macrothink Institute"}

Cass

Journal of Biology and Life Science ISSN 2157-6076 2012, Vol. 3, No. 1

http://www.casscountynd.gov/county/depts/sheriff/corrections/Pages/Fingerprints.aspx

Cummins H, Midlo C. (1926). Palmar and plantar epidermal ridge configurations (dermatoglyphics) in European-Americans. American Journal of Physical Anthropology, 9, 471-502. http://dx.doi.org/10.1002/ajpa.1330090422

Henry Edward R. Sir. (1900). Classification and Uses of Finger Prints. London. George Rutledge \& Sons Ltd.

Kanhere AM. How does finger print work. [Online] Available: http://www.buzzle.com/articles/how-does-fingerprinting-work.html

Kiran. K, Kavitha Rai, Amitha M Hegde. (2010). Dermatoglyphics as a noninvasive diagnostic tool in predicting mental retardation. JIOH. 2, 95-100.

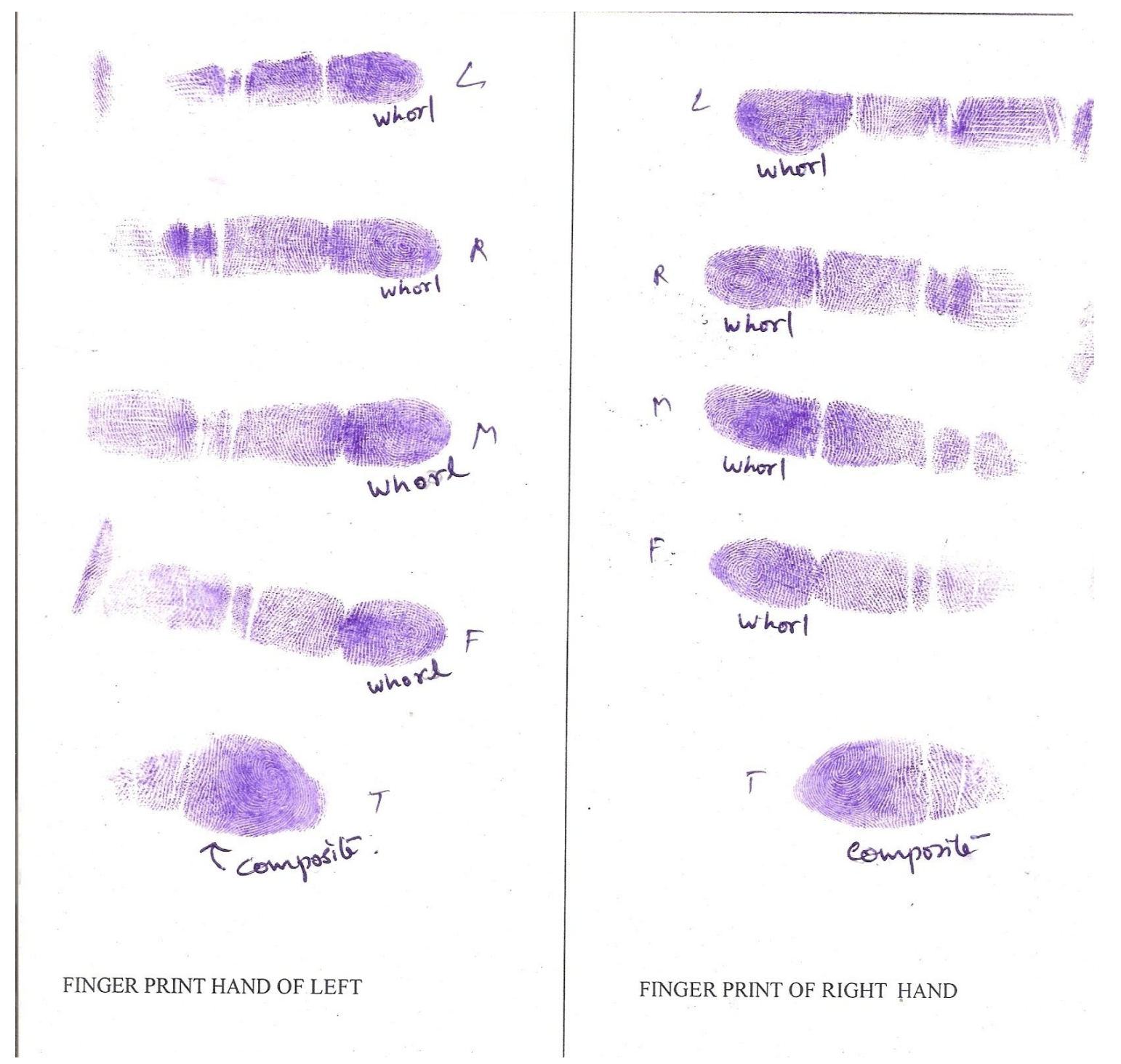

Figure 1. Depicting more number of whorls pattern in control group. 


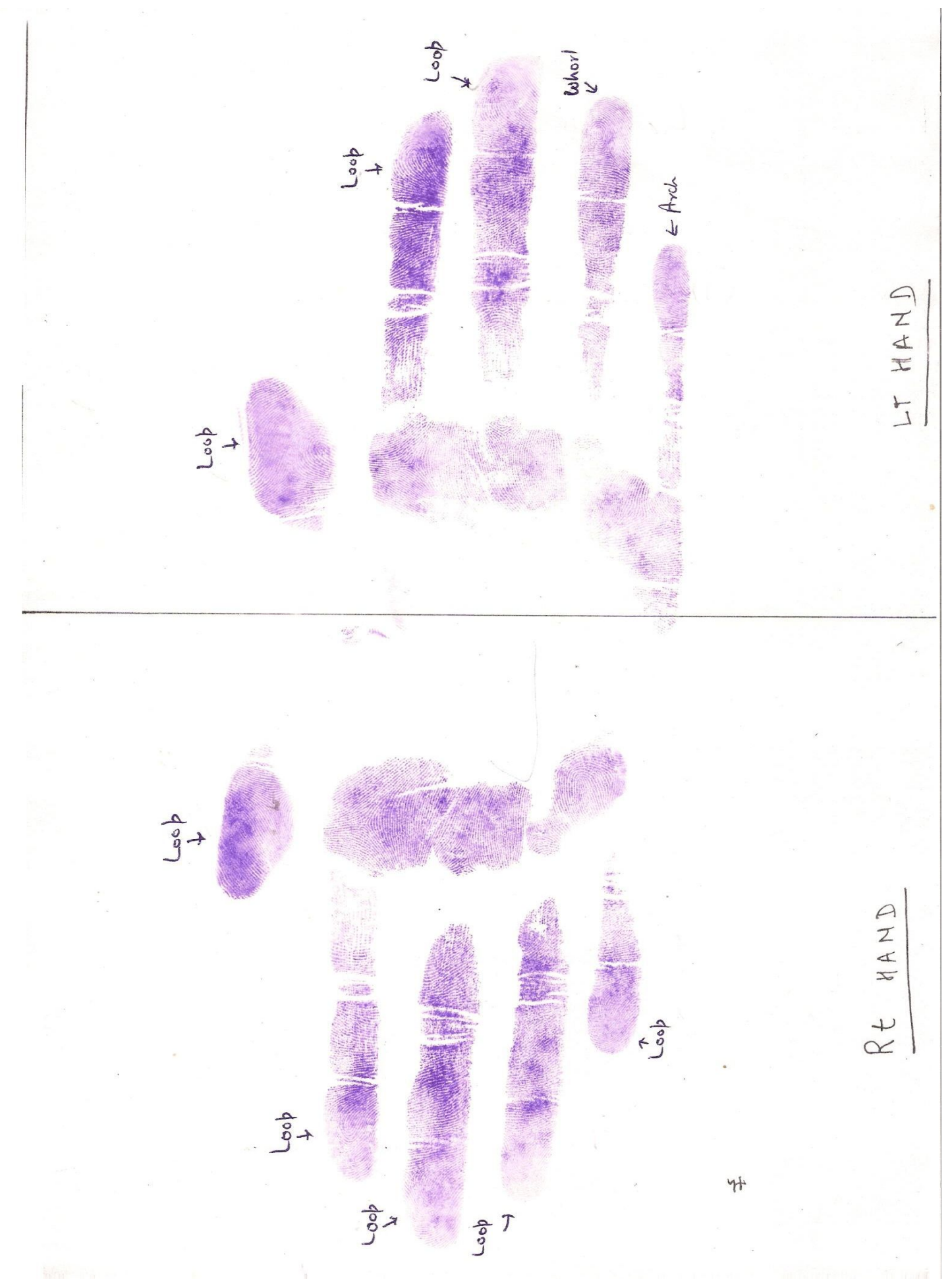

Figure 2. Showing more number of loops in prisoner hand 


\section{Copyright Disclaimer}

Copyright reserved by the author(s).

This article is an open-access article distributed under the terms and conditions of the

Creative Commons Attribution license (http://creativecommons.org/licenses/by/3.0/). 